\title{
Application of fracture mechanics for weld integrity assessment
}

\author{
V R RANGANATH and S TARAFDER \\ Fracture \& Fatigue Group, Materials Evaluation Division, National Me- \\ tallurgical Laboratory, Jamshedpur 831007 , India
}

\begin{abstract}
The structural integrity assessment of a weld joint by conventional techniques is inadequate, because of unavoidable defects in the weld composite. The stress situation in a component having a defect is quite different from that of a homogeneous material. The significance of fracture mechanics to deal with such integrity assessments is brought out. A brief review on the basic formulations in the application of fracture mechanics is followed by established guidelines for evaluating the integrity of engineering components containing crack-like defects.
\end{abstract}

Keywords. Fracture mechanics; integrity assessment; welding; crack tip opening displacement; $J$-integral; fracture toughness; stress intensity factor.

\section{Introduction}

The advent of high toughness structural materials necessitated a corresponding research in the area of welding - the process which is extensively used in fabrication. The specific properties that characterize a good weld are the homogeneity of the weldment and matching strength of the weld joint to that of the base metal. While these properties are not difficult to achieve in the weld metal zone, in the zone lying between the weld zone and the base metal, termed as the heat affected zone (HAZ), control of property is often difficult to achieve. The successive heating and cooling of the HAZ during multipass welding could result in a microstructure which is prone to brittle fracture (Lancaster 1980). In fact, a number of catastrophic failures, resulting in huge losses in terms of personnel and financial, have been reported to have originated from the HAZ of weld joints (Williams \& Ellinger 1953; Bennett \& Mindlin 1973; Ghosh et al 1990).

In order to evaluate the health of a weld joint, a number of test procedures have been evolved (ASW 1990). Depending on the convenience and mutual agreement between the manufacturer and the consumer, conventional tests, like the ' $v$ ' bend test for assessing the ductility, and controlled thermal severity test (CTS) for assessing tendency towards cold cracking are generally carried out. These tests, however, serve to qualitatively assess the weld joint as a whole. For a more objective and scientific assessment of the weld joint, the composite comprising three zones that constitute the weld joint, viz., the base metal, the HAZ and the weld metal, have to be individually 
assessed with regard to their tendency to cracking (Ranganath et al 1991). It is now widely recognized that any weld joint will invariably contain defects. Defects could arise due to improper welding e.g., voids, slag entrapments, or under-cutting. An incipiently embrittled HAZ microstructure may also be considered as a defect (Barsom \& Rolfe 1987a). During service, all the defects in a weld composite are candidate sites for cracks to initiate. Once initiated, the cracks grow through a component, following a path of least resistance, leading to failure. A recent tool in analysing and characterizing the behaviour of cracks is fracture mechanics. The theoretical and functional basis of fracture mechanics has been sufficiently well developed in order for it to be applied to the prediction and prevention of service failures in engineering components. The present paper explores the use of fracture mechanics in failure analysis, life estimation and integrity assessments, with particular reference to weldments.

\section{Origin of fracture mechanics}

Many engineering components fail much below their design stress level, even though they are designed and inspected as per the relevant codes. This is because cracks or crack-like defects are always present in the material/component and failure is a result of such cracks extending to their critical length. The incipient flaws, which act as cracks or crack initiators, severely affect the local stress field and the severity of the stress near and around these flaws could be significantly higher than the design stress (Kanninen \& Popelar 1985). Usually, general design practices do not take such stress intensities into account while calculating the design stresses. Fracture mechanics originates from this lacunae and provides the basis by which the effects of intensified stresses on the integrity of components can be accounted for.

\subsection{Modes of failure in a cracked body}

The modes of failures are schematically shown in figure 1 . The three modes are represented as I for opening mode (tensile stress in $y$ direction), II for edge sliding mode (shear stress in $z$ direction) and III for screw-sliding mode (shear stress in $x$ direction). In metals, most of the crack-related failures occur in mode I. Hence, mode I fracture is widely discussed (Knott 1973).

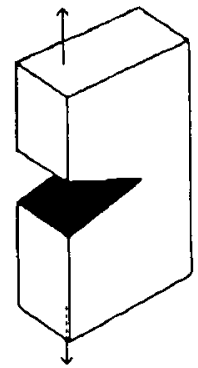

Mode I- Opening

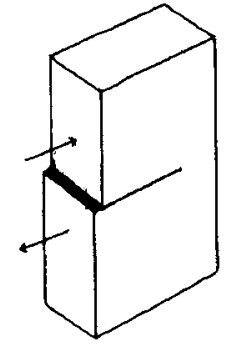

Mode II - Sliding

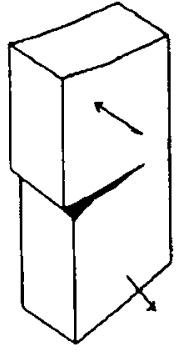

Mode III - Tearing
Figure 1. Various modes of loading. 


\subsection{Stress intensity factor}

The stress intensity factor (SIF) is a term coined to characterize the stress magnitude around the crack tip, in a cracked body, and is denoted as $K$. Although in-service components encounter a mixture of modes I, II and III stresses, the contribution of stresses of modes II and III to the fracture process is negligible. Due to this reason, the SIF is indicated as $K_{\mathrm{I}}$, implying opening type of loading (mode I, tensile) on the crack faces. When the stress intensity approaches a critical value beyond which the stressed component fails in a catastrophic manner, the applied stress intensity, $K_{1}$, is termed as $K_{\mathrm{Ic}}$. This $K_{\mathrm{Ic}}$ is called as critical stress intensity factor. Analogous to yield stress, $\sigma_{y}, K_{\mathrm{Ic}}$ is a material property. Customarily, it is known as plane-strain fracture toughness and indicates the material's resistance to crack propagation. Mathematically, the SIF is represented as (Broek 1986):

$$
K_{\mathrm{I}}=\sigma a^{0-5} f(g)
$$

where $\sigma$ is the applied stress, $a$ is the crack depth and $f(g)$ is a factor depending on the geometry of the stressed component.

As can be seen from (1), $K_{1}$ is a function of load, geometry of the component and size of the crack. A number of relationships between the SIF and various body configurations, for varying crack sizes, orientations, shapes and loading conditions are available from hand books (Tada et al 1973; Rooke \& Cartwright 1976).

\subsection{Determination of SIF}

Stress intensity factors can be calculated by using numerical methods such as weight function, boundary collocation and finite element methods (Kanninen \& Popelar 1985). Whereas in these techniques most of the conditions are idealized, the experimental techniques narrow the gap between a service component stress field history and the laboratory calibration.

A variety of test specimen geometries can be used to determine the fracture toughness, $K_{\mathrm{Ic}}$, of metallic materials as described in ASTM (1992a). Two of the most popular specimen geometries are the compact tension and the three-point bend specimen. Figure 2 shows a schematic of these specimens.

2.3a Test procedure: In order to produce a sharp crack, so that the situation in a service component may be simulated, the test specimen is first subjected to fatigue pre-cracking under predominantly linear elastic loading conditions. The crack length, $a$, thus generated should be about half of the specimen width, $W$. The specimen is then loaded monotonically till it fractures completely. An autographic load vs. displacement plot obtained during loading is then analyzed for $K_{\mathrm{Ic}}$. A typical plot of such a test is shown in figure 3 .

The load point identified as $P_{q}$ in the plot is considered as critical load at which crack extension starts. From $P_{q}$ onwards, up to the maximum load, the crack extends in a stable manner, beyond which it becomes unstable. A tentative fracture toughness $K_{q}$ is calculated as:

$$
K_{q}=[P / B(W-a)] a^{0.5} F(a, W) .
$$



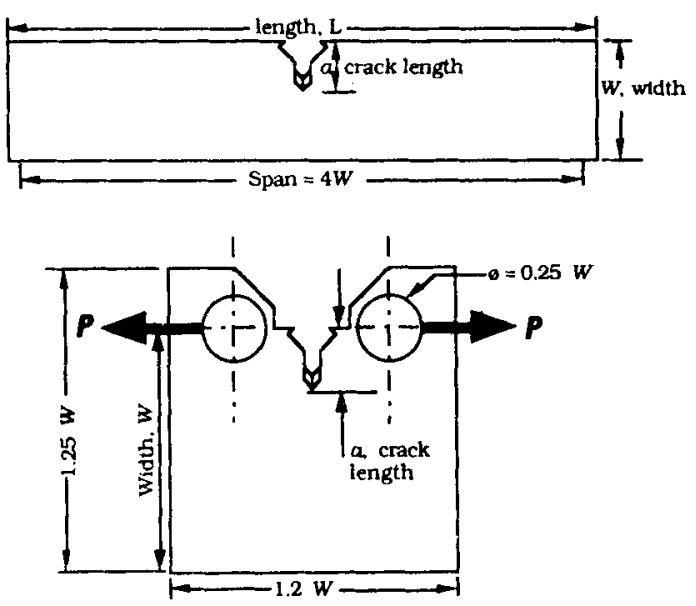

Figure 2. Popular fracture mechanics test specimen geometries. (a) Three point bend specimen; (b) compact tension specimen.

If the specimen thickness, $B$, and the crack length, $a$, are greater than $2 \cdot 5\left(K_{q} / \sigma_{y}\right)^{2}$, the $K_{q}$ is validated as $K_{\mathrm{lc}}$ which has units of $\mathrm{MPa} \mathrm{m}^{0.5}\left(\mathrm{MNm}^{-1.5}\right) . K_{\mathrm{lc}}$ is a material property and is independent of size and geometry of the specimen.

Having known $K_{1 \mathrm{c}}$ of a material, it can be readily applied to evaluate the criticality of a crack detected in a service component during routine inspection by employing the equation:

$$
a_{c r}=\left[K_{\mathrm{Ic}} /(\sigma F(a / W))\right]^{2},
$$

where $a_{c r}$ is the critical crack length, $K_{\text {Ic }}$ is the plane-strain fracture toughness, $\sigma$ is the net section stress and $F(a / W)$ is the specimen geometry factor, based on crack length to width ratio. Depending on the difference between the detected crack length and the calculated critical crack length, as per (3), decisions can be taken on immediate replacement or time interval for next inspection.

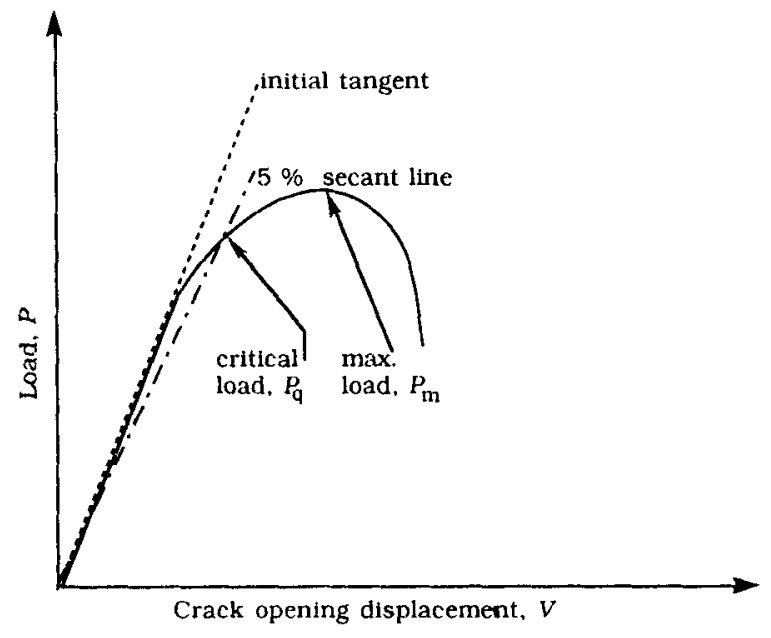

Figure 3. Schematic load displacement curve and the terminology related to a $K_{\mathrm{tc}}$ test plot. 
With the advent of high toughness materials, $K_{\mathrm{Ic}}$ was found to be inadequate to represent fracture toughness because linear elastic conditions are not preserved at the tip of cracks so that a crack in these materials may not start growing even at the maximum load. To characterize such high toughness materials, the concepts of $J$-integral and crack opening displacements have been introduced (Knott 1973).

\section{Other fracture toughness parameters}

\section{$3.1 \quad J$-Integral}

A simplest definition of $J$-integral can be stated as a measure of energy absorbed by a cracked body. The $J$ value, in a laboratory specimen, is calculated by measuring the area under the load-displacement curve, the test procedure being similar to that of a $K_{\mathrm{lc}}$ test. The equation used is of the form:

$$
J_{\mathrm{I}}=A \alpha /(B(W-a)),
$$

where $A$ is the area under the load--displacement curve and $x$ is a factor depending on the specimen geometry and is obtainable from handbooks. Like $K_{\mathrm{lc}}, J_{\mathrm{lc}}$ indicates the critical fracture toughness value at which a fresh crack surface starts forming in a body and is a material property, having units of $\mathrm{kJm}^{-2}$. The appropriate standard for $J_{\mathrm{ic}}$ testing is ASTM (1992b).

\subsection{Crack tip opening displacement}

For a cracked body under stress, the crack tip opening displacement (CTOD, $\delta)$ is the extent of opening at the crack tip. On the application of stress to the component, the crack tip undergoes elastic opening, blunting and then the crack extends. The amount of opening at the start of crack propagation is known as critical crack tip opening displacement, $\delta_{\mathrm{Ic}}$. Experimentally, the CTOD is calculated from the opening measured at the crack mouth in a loaded specimen (BSI 1979; ASTM 1992c). The mouth opening displacement (MOD) is measured by a clip-on-gauge. The equation for calculating the CTOD is given in figure 4 , which is a schematic of three-point bend specimen under load.

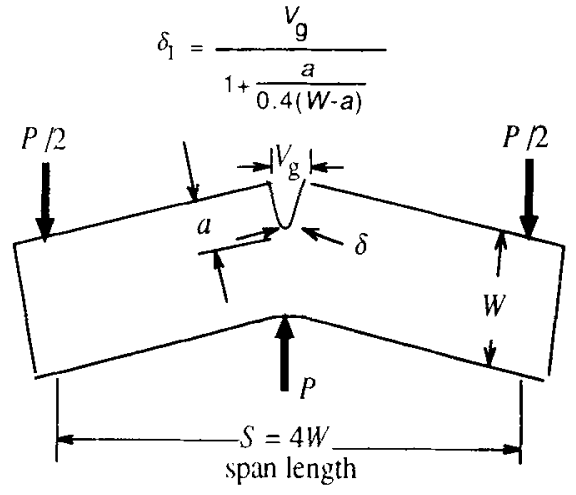

Figure 4. Three point bend specimen under load. 


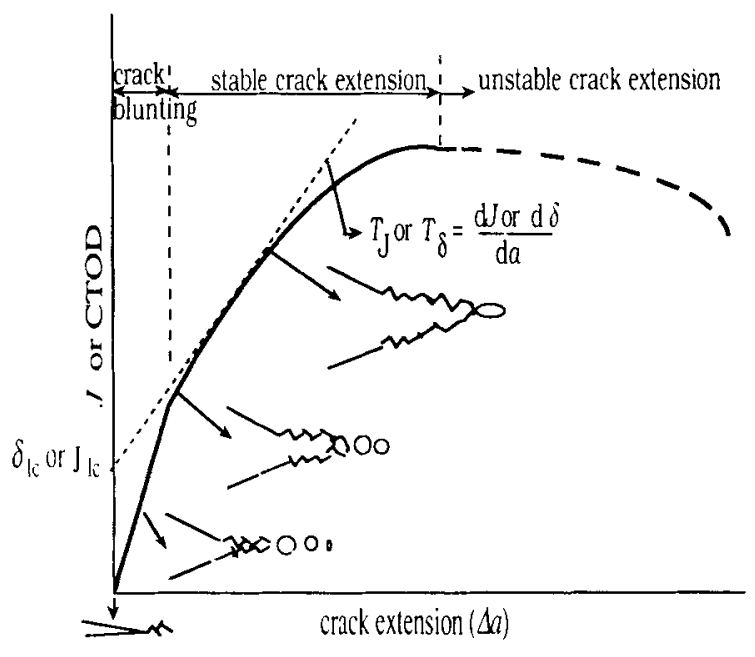

Figure 5. A schematic crack growth resistance curve.

There exist a number of inter-relations between $K, J$ and $\delta$, knowing any one, the other parameters can be calculated.

$$
\delta_{\mathrm{Ic}}=\left(J_{\mathrm{Ic}}\right) /\left(2 m \sigma_{y}\right)=\left(K_{\mathrm{lc}}^{2}\right) /\left(m E \sigma_{y}\right)
$$

In the above equation, $m$ is a constraint factor and depends on the strain hardening behaviour of the material.

The CTOD concept has gained popularity, particularly for assessment of weldments, because it is believed that the local crack tip environment is better represented by CTOD and in the heterogeneity associated with a weldment, the local environment may vary considerably.

\subsection{Crack growth resistance curves}

The parameter $J$ is very useful for developing crack growth resistance curves, generally known as $R$-curves. A schematic of the $R$-curve is presented in figure 5 .

These curves represent the complete characterization, i.e., initiation and propagation, of the flaw. The slope of the stable tearing regime is termed as tearing modulus, $T_{j}$, having units of $\mathrm{MPa}$, and indicates the material's resistance to crack propagation. Once these curves are obtained from laboratory tests for a given material, $J$ values could be computed for an existing crack in a component under service, and the behaviour of the crack, as to whether the flaw is stable or approaching instability can be predicted from the $R$-curve (Turner 1983).

\section{Guidelines for fracture assessment}

Several leading organizations have developed guidelines for assessment of defects in components, based on one of the fracture parameters discussed above. Some of these are: An engineering approach for elastic-plastic fracture analysis (Kumar et al 1984) by Electric Power Research Institute (EPRI) and Guidance on methods for assessing the 
acceptability of flaws in fusion welded structures (Garwood 1985) by Central Electricity Generation Board (CEGB). The latter has been the most popular, with particular reference to weldments, and the British Standards Institution has published a document, PD 6493 (BSI 1991), to streamline procedures for fracture assessment. Salient features of the document are discussed here.

The PD 6493 guidelines are provided for three levels of assessment and are based on CTOD design curves. The levels are in the increasing complexity of the treatment. Level 1 is an initial screening level and provides a simplified method of checking whether particular flaws present a fracture problem, or whether the flaws can be considered safe without having to use the more complex assessment procedures. Level 2 is full treatment and is based on the use of an assessment diagram which combines consideration of fracture and local plastic collapse. It gives the user an opportunity to assess the safety margins required. The level 3 approach will permit greater accuracy but involves greater complexity and more material data. It is particularly appropriate where failure occurs by ductile tearing (high work hardening).

\subsection{Information required for assessment}

Before the treatment of three levels of assessment. the essential data required for this purpose can be listed as:

(a) position and orientation of flaw (NDE);

(b) structural and weld geometry, welding procedure (fabrication);

(c) stresses and temperatures including transient (all loadings including those arising during transport, erection and testing, local loads, misalignments, structural discontinuities, membrane stress, bending stress, thermal and residual stress, peak stress);

(d) material properties (yield and tensile strength, Young's modulus);

(e) fatigue data ( $S-N$ curves, Paris constants);

(f) fracture toughness ( $K_{\text {Ic }}$, CTOD, impact toughness);

(g) high temperature behaviour of material (creep rupture, creep fatigue, creep crack propagation data);

(h) Corrosion data (bulk corrosion, stress corrosion cracking i.e., $K_{\mathrm{ISCC}}$ ).

Once the information as above is obtained (from laboratory tests, stress analysis, assumptions based on experience, service conditions and NDE), the assessment is carried out. at different levels, as discussed below.

\subsection{Level 1, preliminary assessment}

4.2a Estimation of the acceptability of a known flaw: Applied CTOD is calculated as:

$$
\delta_{\mathrm{I}}=\left(K_{\mathrm{I}}^{2} / \sigma_{y}\right) E=\left(\sigma_{\mathrm{l}}^{2} \pi a\right) /\left(\sigma_{y} E\right),
$$

where $a$ is the flaw length and $\sigma_{1}$ is the applied maximum tensile stress.

The flaw is acceptable if $\delta_{r}^{0.5}$ (ratio of applied CTOD, $\delta_{1}$, to that of $\delta_{\mathrm{Ic}}$ of the material) is less than 0.707 and $S_{r}$, plastic collapse ratio, (ratio of net section stress, $\sigma_{n}$, to that of flow stress, $\sigma_{f}$, of the material) is less than $0 \cdot 8$. Since this is a level 1 approach, no additional safety factor is required. 
4.2b Estimation of acceptable flaw size: The equivalent tolerable flaw parameter $a_{m}$ is given as:

$$
a_{m}=\left(\delta_{\mathrm{Ic}} E\right) /\left[2 \pi\left(\sigma_{1} / \sigma_{y}\right)^{2} \sigma_{y}\right]
$$

The relationship already includes a variable safety factor, averaging about 2 . The flaw parameter, $a_{m}$, may represent a variety of flaw shapes and dimensions of equivalent severity. Having obtained the flaw parameter, equivalent part-thickness embedded flaw and surface flaw dimensions can be derived from the figure 6.
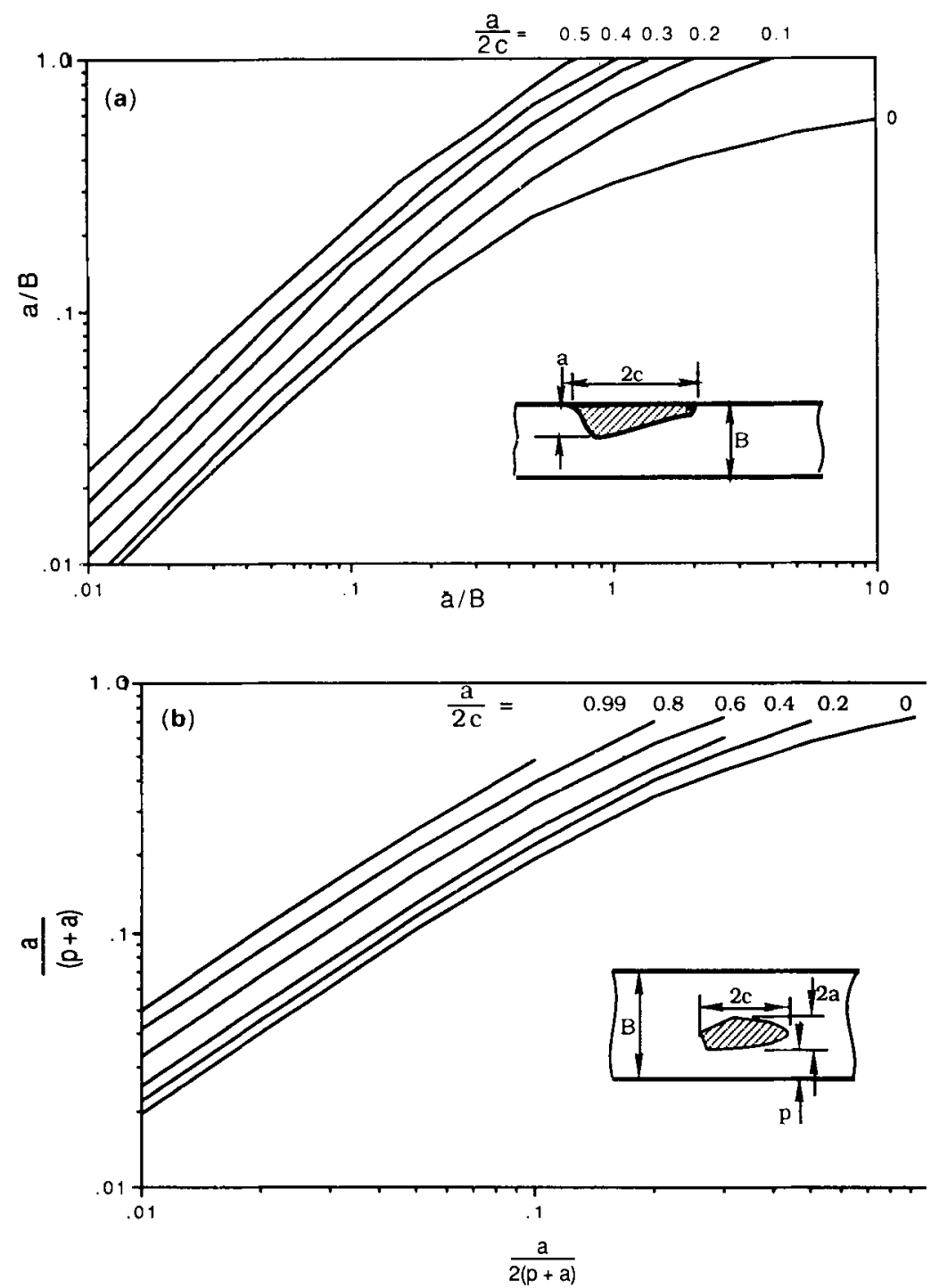

Figure 6. Relationship between actual flaw dimensions and the parameter $\bar{a}$ for (a) surface and (b) embedded flaws. 


\subsection{Level 2, normal assessment}

4.3a Estimation of the acceptability of a known flaw: In the level 1 assessment only primary stresses are considered. At level 2 , secondary stress is also taken into account while calculating $\delta_{1}$ as per $(6)$. Further, the parameter $\delta_{r}$ is calculated as:

$$
\delta_{r}^{0 \cdot 5}=\left(\delta_{1} / \delta_{\mathrm{Ic}}\right)^{0 \cdot 5}+\rho
$$

where $\rho$ is a correction factor for plasticity interactions of the primary and secondary stresses.

The plastic collapse ratio, $S_{r}$, is calculated as previously. Using the level 2 assessment diagram shown in figure 7 , the point represented by $\left(\delta_{r}^{\frac{1}{2}}, S_{r}\right)$ is marked on the plot. If the marked point lies within the assessment curve, then the flaw is acceptable. If the point lies on or outside the line, the flaw is not acceptable.

4.3b Estimation of limiting flaw size: The limiting flaw size $a_{m}$ is defined by a computed point which lies on the failure assessment line given in figure 7 . It may be obtained by plotting a series of calculated points for various sizes, and noting the flaw size at which the appraisal point falls on the assessment line.

\subsection{Level 3, advanced assessment}

The level 3 method makes use of assessment diagram derived from the stress/strain curve of the material. This allows advantage to be taken of any high work hardening characteristics of the material which may prevent failure. A partial safety factor may be applied depending on the consequence of failure. For example, the safety factor may be taken to be moderate if local failure does not cause complete structural collapse or it may be taken to be severe if there is risk of complete structural collapse resulting in severe hazard.

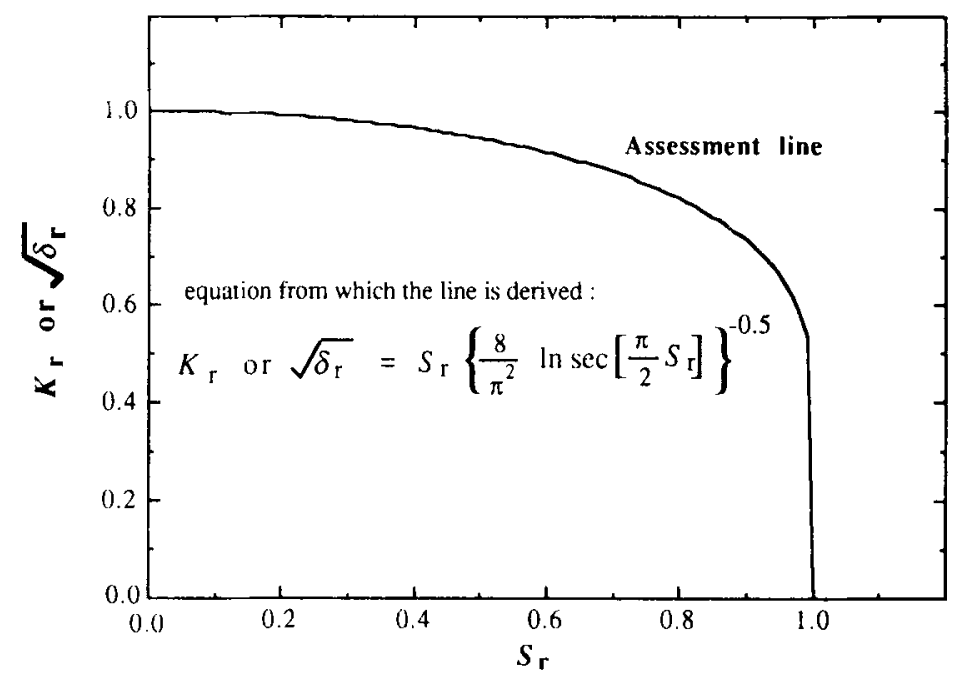

Figure 7. Estimation of acceptability of a known flaw (level 2). 
4.4a Assessment diagram: The assessment diagram is constructed by plotting values of $\delta_{r}$ calculated from:

$$
\delta_{r}^{0.5}=\left[\frac{E \ln (1+\varepsilon)}{\sigma(1+\varepsilon)}+\frac{\sigma^{3}(1+\varepsilon)^{3}}{2 \sigma_{y}^{2} E \ln (1+\varepsilon)}\right]^{-0.5}
$$

against $L_{r}$ defined as the ratio $\sigma(1+\varepsilon) / \sigma_{y}$, where $\sigma, \varepsilon$ are stress and strain, respectively, of the structure or the component, and $\sigma_{y}$ is the yield stress. The assessment diagram for level 3 is shown in figure 8 . This failure analysis diagram can be adopted where the stress/strain curve is uncertain (e.g., HAZ regions) and for all materials which do not exhibit a yield discontinuity in the stress/strain curve.

4.4b Estimation of acceptability of a known flaw: When $\delta_{\mathrm{Ic}}$, a single value of toughness of the material, is known, the parameter $\delta_{r}$ is calculated as per (8) as a component of the assessment point. Equation (9) is used for calculating $\delta_{r}^{0 \cdot 5}$ while constructing the failure assessment diagram. The value of $L_{z}$ is the ratio of net section stress to that of yield stress. Note that the denominator is the yield stress, as compared to the flow stress while calculating $S_{r}$ in level $1 \& 2$ approaches. The resulting point $\left(\delta_{r}\right.$, $\left.L_{r}\right)$ is plotted on the failure assessment diagram. If the point lies within the assessment curve, then the flaw is acceptable, if the point lies on or outside the line, then the flaw is not acceptable.

4.4c Estimation of limiting initial flaw size: The limiting flaw size, $a_{c r}$, is that flaw size which touches the failure assessment line tangentially when a locus of all possible assessment points is drawn. All the other points on the locus lie outside the area bounded by the axes and the assessment line. This corresponds to the limiting load

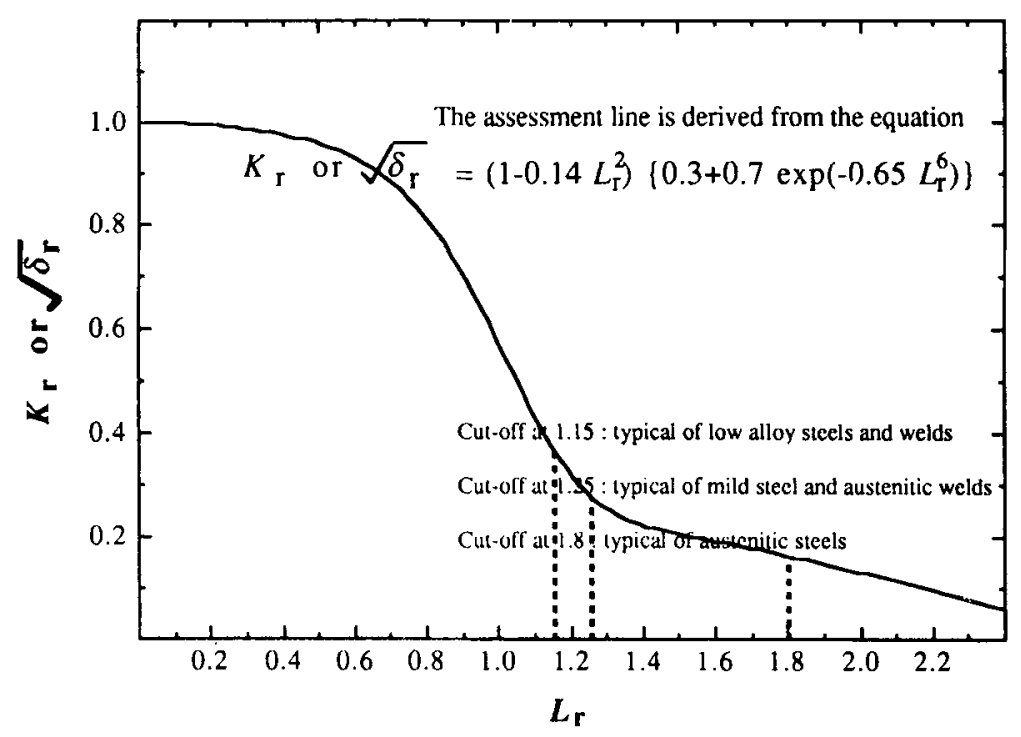

Figure 8. Level 3 failure assessment diagram when complete stress/strain data are available. 
factor, $F_{l}$ (ratio of limit load to that of applied load) equal to unity, and is most easily obtained from a plot of $F$ as a function of initial flaw size.

\section{Assessment for fatigue cracks}

In components subjected to fatigue loading, flaws can originate from any of the existing defects e.g., stress concentrators, inclusions, misalignments, machining/welding defects etc. Most of the life of such components is spent at the crack initiation stage itself. Once the crack has initiated, it grows steadily and the crack growth in this stage can be represented by the Paris Law, which can be mathematically stated as:

$$
\mathrm{d} a / \mathrm{d} N=A(\Delta K)^{n}
$$

where, $\mathrm{d} a / \mathrm{d} N$ is the crack growth per cycle, $\Delta K$ is the operating stress intensity range (difference between maximum and minimum operating stress intensity) and $A$ and $n$ are material constants obtained from laboratory tests. Schematically, the Paris Law is shown in figure 9.

In a laboratory test (ASTM 1992d), standard specimens from the material of interest are loaded in fatigue. During the test, the crack increment is monitored along with the number of cycles. $\Delta K$ is calculated from the specimen size, load levels and the crack length at a given instant. The Paris constants, $A$ and $n$ are calculated respectively, from

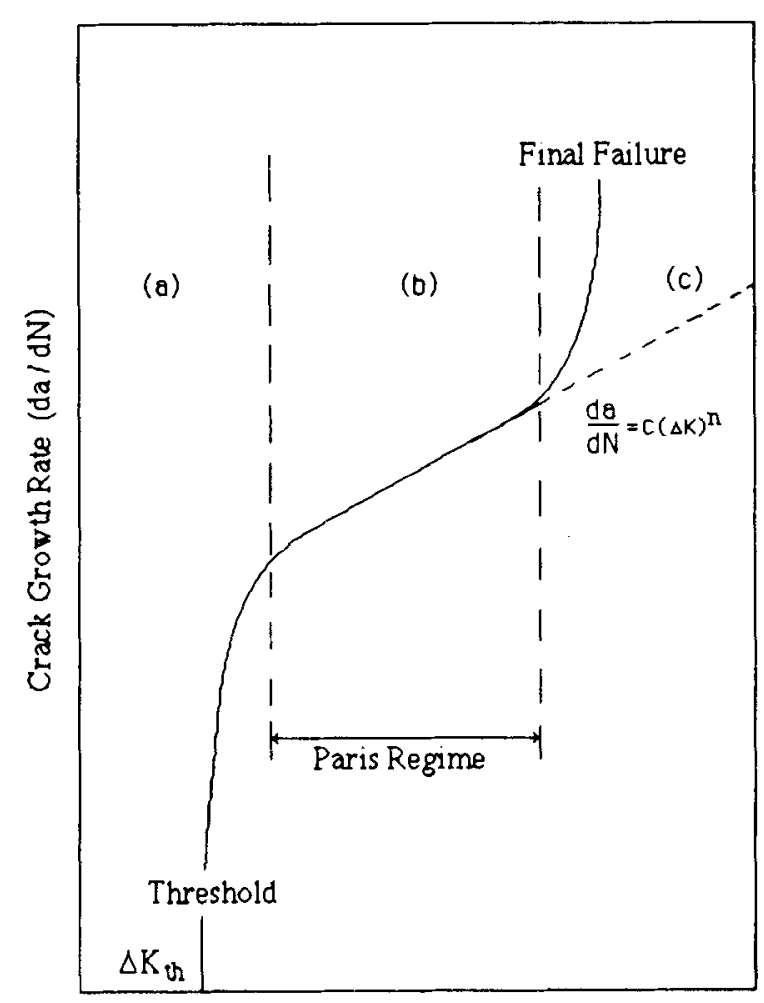

Alternating Stress Intensity $(\Delta K)$
Figure 9. Schematic representation of fatigue crack growth rate data showing Paris regime. 
the intercept and slope of the linear portion of the $\mathrm{d} a / \mathrm{d} N$ vs $\Delta K$ plot. From the plot in figure 9 , it is seen that the fatigue crack growth rate curve has three distinct regimes. If the operating stress levels are below $\Delta K_{t h}$, the threshold stress intensity factor range, the component has infinite life. If the operating stresses are approaching $K_{c}$, as in regime III, the component has negligible life and needs immediate replacement. In regime II, which is also known as Paris regime, the crack grows in a steady state manner and the remaining life of the component can be predicted, by separating the variables and integrating for $N$

$$
N_{f}=\int_{0}^{N} \mathrm{~d} N=\int_{a_{\mathrm{i}}}^{a_{c r}} \mathrm{~d} a /\left(A(\Delta K)^{n}\right) .
$$

In the above equation, $N_{f}$ gives the total life (in terms of cycles), $a_{i}$ is obtained from nondestructive examination of the component, the critical crack length, $a_{c r}$ is obtained from (3).

Once the flaw dimensions and orientations are known using standard non-destructive examination methods, the flaws are resolved as per the direction of the acting stresses. Various guidelines on flaw resolutions and assumptions are described in PD 6493 (BSI 1991) and some stress analysis handbooks. The flaw, thus identified, the operating stress cycles and the limiting flaw dimension are the data required for fatigue assessment. Fatigue life is then calculated as per(11). Where the constants $A$ and $n$ are not available for a particular material, they may be taken as $A=3 \times 10^{-13}$ and $n=3$ (for $\mathrm{d} a / \mathrm{d} N$ units of $\mathrm{mm} /$ cycle; $\Delta K$ units of $\mathrm{Nmm}^{-3 / 2}$ ) for all ferritic steels operating in air or other non-aggressive environments at temperatures up to $100^{\circ} \mathrm{C}$. For structural ferritic steels operating in a marine environment, in the absence of specific corrosionfatigue data, the crack growth constants may be taken as: $A=2.3 \times 10^{-12}$ and $n=3$. These values correspond to the upper bound values of all the published data. For carbon and carbon manganese steels, analysis of published data shows that $\Delta K_{\text {th }}$ (stress range below which crack does not grow) is about $63 \mathrm{Nmm}^{-3 / 2}$. In welded joints, if the residual stress $\left(\sigma_{R}\right)$ is not available, it is assumed to be of yield strength magnitude. In the absence of data, on a particular material, $\Delta K_{t h}$ of $63 \mathrm{Nmm}^{-3 / 2}$ may be assumed for weldments. Where the materials are non-ferrous and the specific data are not available, as a first approximation, the constants can be calculated as:

$$
A=3 \times 10^{-13}\left[\frac{E_{\text {steel }}}{E_{\text {matl. }}}\right]^{3} .
$$

Similarly the threshold stress intensity factor can be obtained as:

$$
\Delta K_{t h}=\Delta K_{\text {th(stee) })}\left[\frac{E_{\text {steel }}}{E_{\text {matl. }}}\right] \text {. }
$$

\section{Special requirements for assessing weldments}

Fabrication by welding induces complex three-dimensional residual stresses that are caused by the heating and cooling effects on the parent metal adjacent to the weld pool. Proper fit-up of adjacent pieces, sequencing and positioning of the weld and preheating or postheating (stress relieving) of the weld assembly would minimize the residual stress. In weldments, the potential crack starters are internal imperfections, such as porosity, lack of fusion, trapped slag, weld toes, weld terminators (Signes et al 1967; 
Fisher 1970; Watkinson et al 1970). However, the existence of tolerable imperfections cannot be avoided and in some cases, attempts to remove these imperfections may result in a condition worse than the original condition (Barsom \& Rolfe 1987b).

When conducting fracture toughness tests on heat affected zone regions, considerable variability can occur due to location of the crack tip in different microstructural regions. It is necessary to carry out sectioning of specimens for tests on $\mathrm{HAZ}$ regions after testing to determine the precise location of the crack tip. In cases where the HAZ toughness cannot be assessed, it can be assumed to be the lower of the toughness value of the adjacent weld metal or parent metal.

For assessing as-welded assemblies, the tensile residual stresses may be assumed to be equal to yield-strength of the material, for flaws lying in a plane transverse to the welding direction. For structures subjected to postweld heat treatment, the level of residual stress may be assumed to be $30 \%$ of the yield-strength. The desirability of having appropriate accurate fracture toughness data cannot be emphasised too strongly, and it is vital that toughness data be obtained from weld procedure samples at the time of construction and recorded if there is any likelihood of flaw assessment being required at any later stage.

\section{Concluding remarks}

The stress situation in a flawed component under stress is quite complex as compared to a homogeneous component under identical stress. Lack of knowledge on behaviour of cracks in weldments has led to severe catastrophic failures in the past. Optimum decisions on retiring a component with a crack, or to continue in operation, could be based on fracture mechanics concepts. These concepts are particularly effective in dealing with integrity assessment of weldments wherein defects are most common. Fracture toughness evaluation has now been standardized by ASTM and BSI. The developments in this area are now at a stage where they are being used routinely in space and nuclear engineering components. Guidelines and a few specific software codes have also been evolved for fracture assessment by shop-floor inspection engineers with minimum exposure to principles of fracture mechanics.

\section{References}

ASTM 1992a Test method for plane strain fracture toughness: E-399. Annual hook of ASTM standards (Washington, DC: ASTM) vol. 03.01

ASTM 1992b Standard test method for $J_{\mathrm{kc}}$ measure of fracture toughness: E-813. Annual book of ASTM standards (Washington. DC: ASTM) vol. 03.01

ASTM 1992c Standard test method for crack tip opening displacement measurement of fracture toughness: E-1290. Annual book of ASTM standards (Washington. DC: ASTM) vol. 03.01

ASTM 1992d Standard test method for measurement of fatigue crack growth rates: E-647. Annual hook of ASTM standards (Washington, DC: ASTM) vol. 03.01

ASW 1990 American Society for Welding Handbook (Miami, FL: ASW) vol. 1-3

Barsom J M, Rolfe S T 1987a Fatigue and fracture prevention and control in structures (Englewood Cliffs, NJ: Prentice Hall) 6: 202

Barsom J M, Rolfe S T $1987 \mathrm{~b}$ Fatigue and fracture prevention and control in structures (Englewood Cliffs, NJ: Prentice Hall) 14: 446

Bennett J A, Mindlin H 1973 Material aspects of failure of Point Pleasant bridge. J. Test. Eval. 1: 152-161 
BSI 1979 British Standards Institution. Methods for COD testing: BS-5762

BSI 1991 British Standards Institution. Guidance on methods for assessing acceptability of flaws in fusion welded structures, PD: 6493 (UK: BSI)

Broek D 1986 Engineering fracture mechanics: Principles and fundamentals (Amsterdam: Martinez-Noordhaf)

Fisher J W 1970 Effect of weldments on the fatigue strength of steel beams. Transportation Research Board (USA), Report no. 102

Garwood S J 1985 A CTOD method for the analysis of ductile materials. In Proc. Fracture Mechanics: 18th symposium, ASTM Standard Technical Publications 945

Ghosh R N, Ranganath V R, Prasad K, Sinha A N 1990 Investigation on structural integrity of Horton sphere. National Metallurgical Laboratory. Report no. 11620024

Kannien M F, Popelar C H 1985 Advanced fracture mechanics (New York: Oxford University Press) chap. 1

Knott J F 1973 Fundamentals of fracture mechanics (London: Butterworths)

Kumar V, German M D 1984 Advances in elastic-plastic fracture analysis. EPRI report no. 3607

Lancaster J F 1980 Metallurgy of welding 3rd edn (London: George Allen and Unwin) chap. 4

Ranganath V R, Kumar A N, Pandey R K 1991 Fracture toughness characterisation of a weldment in a microalloyed steel using resistance curves. Mater. Sci. Eng. A132: 153-160

Rooke D P, Cartwright D J 1976 Compendium of stress intensity factors (London: HMSO)

Signes, Baker R G, Harrison J D, Burdekin F M 1967 Factors affecting the strength of welded high strength steels. Br. Welding J. 14(3): 108-116

Tada H, Paris P, Irwin G 1973 The stress analysis of cracks handbook (Hellertown: Del Res. Corp.)

Turner C E 1983 Further developments of a $J$ based design curve. In Proc. Elastic-plastic fracture: 2nd symposium. Vol. 2: Fracture curves and engineering applications. ASTM Standard Technical Publications 803

Watkinson F, Bodger P H, Harrison J D 1970 The fatigue strength of welded joints in high strength steels and methods for improvement. Proc. Conf. Fatigue of welded structures (Brighton: Welding Inst.)

Williams M L, Ellinger G A 1953 Investigation of structural failures of welded ships. Welding $J$. (Miami) 32: 498s-528s 